\title{
Linkage Map Development in Brassica juncea using SSR
}

\author{
Darshana Patra* \\ Department of Plant Breeding and Genetics, OUAT, Bhubaneswar, Odisha, India \\ *Corresponding author
}

\section{A B S T R A C T}

\begin{tabular}{|l|}
\hline Ke y w o r d s \\
Mustard, Gene \\
pools, SSR, \\
Linkage Map, \\
Genic regions
\end{tabular}

Indian mustard (Brassica juncea L.) is one of the major oilseed crops in India. Increasing demand for edible oil makes it a necessity to increase the productivity of this crop. It is a natural amphi-diploid of Brassica rapa (AA) and Brassica nigra (BB) and is characterized by presence of two distinct gene pools - East European and Indian. The crosses between them have been shown to exhibit heterosis. Therefore, the genetic improvement of the two gene pools by carrying out introgression of desirable characters from one divergent pool to the other is vital in oilseed mustard improvement program. The major breeding objectives of B. juncea mainly lie in the improvement of its oil yield and quality. A dearth of easy-togenotype and gene based molecular markers could be a hindrance in conducting a detailed genetic analysis. To understand the genetic basis of these traits, there is a need to construct a detailed genetic map with high levels of genome coverage. SSR markers designed from the genic regions had gained much importance in the past decade. Very few genic SSR markers had been developed in Brassica species. The present investigation is envisaged to develop a linkage map using microsatellite (SSR) markers.

\section{Introduction}

The Brassicaceae family (also known as mustard or Cruciferae family) belongs to the order Brassicales and tribe Brassiceae is one of them that contain 51 genera including Brassica.

This genus is considered to be one of the ten most economically important plant families (El Naggar, 1987; El Naggar and El Hadidi, 1998).Out of 37 species belonging to the genus Brassica, $B$. junceaor Indian mustard is one of them (Warwick and Al- Shehbaz, 2006; Franzke et al., 2011). It is one of the primary crops under Brassicas.
The basic genus comprises six crop species, each with considerable morphological variations. Three basic diploid Brassica species, B. rapa(A genome, $\mathrm{n}=10), \mathrm{B}$. oleracea $(C$ genome, $n=9)$ and $B$. nigra $(B$ genome, $\mathrm{n}=8$ ), through interspecific hybridization in all possible combinations gave rise to three amphidiploid species $B$. napus (AC genome, $\mathrm{n}=19), B$. juncea ( $\mathrm{AB}$ genome, $\mathrm{n}=18)$ and $B$. carinata (BC Genome, $\mathrm{n}=17)$.

Out of all Brassicas, B.juncea is one of the most important oilseed crops. It is an annual crop with a wide geographical range. It is cultivated worldwide as a condiment, an 
oilseed and a vegetable. India produces bulk of mustard seeds which is mostly used for oilseed production. The oil extracted from the seeds is largely used for edible processes (Edwards et al., 2007, Sharma et al., 2006).

To identify genetic differences between individual organisms or species, genetic markers act as the tools. Molecular markers are less time consuming, user-friendly, a large number of individuals can be genotyped, less costly and the main advantage being there is no radioactivity. DNA sequence in the genome can be located and identified by using a molecular marker. It helps to detect differences among different strains of a species or among different species (Singh B., 2001). There may be variation in the base composition at a particular location in different plants due to genetic alterations like mutations, insertions, deletions, etc. These differences are collectively known as polymorphisms which can be mapped and identified.

The detected gene can be considered as the molecular marker but it is not always possible. Instead, markers which are closely associated with genes and inherited together can be taken.

Conventionally in the breeding programmes, selection of the desired traits and improvement of crops were done, in which identification of phenotypes was predominant. Now it is accepted that the phenotypes do not necessarily represent the genotypes. Mostly genotype may be marked by the environment. Thus, for various reasons the genetic potential of a plant is not truly reflected in the phenotypic expression.

The molecular marker assisted selection is based on the identification of DNA markers that link/ represent the plant traits like resistance to pathogens and insects, tolerance to abiotic stresses and various other qualitative and quantitative traits.

The major requirements for the molecular marked selection in plant breeding are:

The marker should have close linkage with the desired trait.

The marker screening methods must be efficient, reproducible and user-friendly.

The analysis should be economical.

Simple Sequence Repeats (SSRs) otherwise called Microsatellites or Short Tandem Repeats (STRs) are rehashing sequences of the short genomic region that are analyzed by PCR amplification (Singh B., 2001). It is a sort of Variable Number Tandem Repeat (VNTR). SSRs are commonly co-prevailing. They find application as atomic markers, for connection, mapping, identification of cultivar, germplasm protection, hybridity determination, gene pool variation analysis and as a part of STR dissection (Singh B., 2001).

Keeping the importance of $B$. juncea and the microsatellite markers, the present study is designed with an objective to unravel the genetic diversity and relatedness among two different $B$. juncea lines using microsatellite markers.

The identification of the location of particular markers within the genome is done by genetic mapping. Mainly two types of maps are created for analysis of genetic material.

Physical map: helps identify the location of a gene on a chromosome

Linkage map: identifies how particular genes are linked to other genes on a chromosome. It identifies distances from other genes in centiMorgan (cM) or Morgan (M) units. 
Linkage of markers can help identify particular polymorphisms within the genome. These polymorphisms help to indicate minute changes within the genome that may present nucleotide substitutions or rearrangement of the sequence. It is useful to identify a large number of polymorphic distinctions and similar sequence between two species while developing a map.

\section{Materials and Methods}

For any DNA manipulation, good quality DNA is a prerequisite. The basic steps for plant DNA isolation involve disruption of the cell wall, the release of DNA out of cell membrane and nuclear membrane into solution followed by precipitation of DNA. The most commonly used basic plant DNA extraction protocols are those of Dellaporta et al., 1983 and Saghai Maroof et al.,1984 along with many others that are modifications of the components of these protocols to suit a particular tissue type or downscaling them for miniprep.

\section{Experimental Details}

\section{Buffers and Solutions}

\section{Extraction buffer per litre solution}

$100 \mathrm{mM}$ TrisHCl $(\mathrm{pH} 8.0)-12.1 \mathrm{~g}$

$20 \mathrm{mM} \mathrm{Na}_{2}$ EDTA (pH 8.0) - 7.44g

$2 \%(\mathrm{w} / \mathrm{v}) \mathrm{CTAB}-20 \mathrm{~g}$

$1.4 \mathrm{M} \mathrm{NaCl} \quad-81.76 \mathrm{~g}$

1\%(w/v) Polyvinylpyrrolidone (PVP) 40 -

$10 \mathrm{~g}$

Distilled water $-1 \mathrm{~L}$

\section{Precipitation buffer per litre solution}

$50 \mathrm{mM}$ TrisHCl(pH 8.0) - 6g

$10 \mathrm{mM} \mathrm{Na} 2 \mathrm{EDTA}(\mathrm{pH} 8.0)-3.72 \mathrm{~g}$

$1 \%(\mathrm{w} / \mathrm{v}) \mathrm{CTAB}-10 \mathrm{~g}$

Distilled water $-1 \mathrm{~L}$

\section{High Salt TE buffer per litre solution}

$10 \mathrm{mM}$ TrisHCl(pH 8.0) $-0.120 \mathrm{~g}$

$1 \mathrm{mM} \mathrm{Na}_{2}$ EDTA (pH 8.0)- 0.0372

$1 \mathrm{M} \mathrm{NaCl}-5.84 \mathrm{~g}$

Distilled water $-100 \mathrm{ml}$

\section{CTAB (Cetyltrimethyl Ammonium Bromide): 100ml}

$10 \% \mathrm{CTAB}-10 \mathrm{~g}$

$6.7 \mathrm{M} \mathrm{NaCl}-4 \mathrm{~g}$

Distilled water $-100 \mathrm{ml}$

\section{Procedure}

Young fully expanded leaves (1-3g) were taken and crushed in liquid nitrogen. Powdered leaves were transferred to tubes containing $5 \mathrm{ml}$ of extraction buffer and then vortexed. The solution was then incubated in a water-bath at $65^{\circ} \mathrm{C}$ for 15 minutes. $5 \mathrm{ml}$ of $\mathrm{CHCl}_{3}$ : IAA (24:1) was added $(96 \mathrm{ml}$ chloroform $+4 \mathrm{ml}$ isoamyl alcohol $=100 \mathrm{ml}$ ) and vortexed. The contents were centrifuged at $6000 \mathrm{rpm}$ for 7 minutes at room temperature. The clear supernatant was transferred to fresh tubes. $1 \mathrm{ml}$ of $10 \%$ CTAB (warm) was added to the fresh solution and vortexed it. $5 \mathrm{ml}$ Of $\mathrm{CHCl}_{3}$ : IAA was added and vortexed. The contents were centrifuged at 6000rpm for 7 minutes at room temperature. The supernatant was collected in fresh tubes.

$15 \mathrm{ml}$ of precipitation buffer was added and mixed by inverting the tubes gently. The mix was then left at room temperature for 30 minutes. The tubes were centrifuged at 6,000 $\mathrm{rpm}$ for 15 minutes. The supernatant was discarded and tubes were inverted.

The pellets were re-suspended in $500 \mu 1$ of high salt TE buffer and were left overnight. The sample was transferred to eppendorf tubes and centrifuged for 2 minutes at 13,000 $\mathrm{rpm}$. The supernatant was collected into fresh 
eppendorf tubes $(\sim 500 \mu 1) . D N A$ was precipitated by adding approximately 2.5 times ethyl alcohol (100\%) and incubated at $20^{\circ} \mathrm{C}$ for 1 hour.

sThe pellets of DNA were obtained after spinning at 13,000 rpm for 15 minutes, at room temperature. The pellets were washed with $70 \%$ ethyl alcohol $(200 \mu \mathrm{l})$ and then allowed to dry.

The pellets were dissolved in $500 \mu \mathrm{l}$ of water and left for overnight. For purification of extracted DNA equal volume of phenol: $\mathrm{CHCl}_{3}(1: 1)$ and vortexed it. The tubes were centrifuged at $13,000 \mathrm{rpm}$ for 10 minutes. $\mathrm{CHCl}_{3}$ was added to the supernatant and vortexed. The tubes were centrifuged at 13,000 rpm for 10 minutes.

To the supernatant, $1 / 10^{\text {th }}$ of its volume $3 \mathrm{M}$ sodium acetate and 2.5 times the volume absolute alcohol was added. The tubes were then incubated at $-20^{\circ} \mathrm{C}$ for 1 hour.The tubes were centrifuged at $13,000 \mathrm{rpm}$ for 15 minutes. The supernatant was discarded; the pellets were air dried and dissolved in $50 \mu 1$ of Milli Q water.

PCR is an efficient and cost effective method developed by Kary Mullis in 1985 based on using the ability of DNA polymerase to synthesize new strand of DNA complementary to the offered template strand (Edel, 1998). In vitro amplification of DNA fragments from complex DNA samples is done by this enzymatic reaction. There is a need of primer which is added with the first nucleotide because DNA polymerase can add nucleotide only to a $3^{\prime}-\mathrm{OH}$ group which is already present by. A specific region of template sequence thus can be delineated using a primer that needs to be amplified.

\section{Materials used}

The TD mapping population along with the parental lines, TM-4 and Donskaja-IV were genotyped with 14 SSR markers (given below) that were identified to be polymorphic between the parental lines.

\section{Primers}

\begin{tabular}{|c|c|}
\hline Sl.No. & Primer \\
\hline $\mathbf{1}$ & UGM-37 \\
\hline $\mathbf{2}$ & UGM-71 \\
\hline $\mathbf{3}$ & UGM-98 \\
\hline $\mathbf{4}$ & UGM-124 \\
\hline $\mathbf{5}$ & UGM-203 \\
\hline $\mathbf{6}$ & UGM-211 \\
\hline $\mathbf{7}$ & UGM-383 \\
\hline $\mathbf{8}$ & UGM-714 \\
\hline $\mathbf{9}$ & UGM-739 \\
\hline $\mathbf{1 0}$ & UGM-816 \\
\hline $\mathbf{1 1}$ & UGM-850 \\
\hline $\mathbf{1 2}$ & UGM-857 \\
\hline $\mathbf{1 3}$ & UGM- \\
& 1089 \\
\hline $\mathbf{1 4}$ & UGM- \\
& 1097 \\
\hline
\end{tabular}




\section{PCR Components}

\begin{tabular}{|c|c|c|c|}
\hline & Stock concentration & Working concentration/amount & $\begin{array}{c}\text { Volume for 1 } \\
\text { reaction }(\boldsymbol{\mu l})\end{array}$ \\
\hline DNA & $10 \mathrm{ng} / \mu \mathrm{l}$ & $30 \mathrm{ng}$ & 3.0 \\
\hline Buffer & $10 \mathrm{X}$ & $1 \mathrm{X}$ & 2.0 \\
\hline $\mathbf{d N T P s}$ & $10 \mathrm{mM}$ & $800 \mu \mathrm{M}$ & 1.6 \\
\hline Taq & $5 \mathrm{U} / \mu \mathrm{l}$ & $0.7 \mathrm{U}$ & 0.14 \\
\hline $\mathbf{F p}$ & $10 \mathrm{pm} / \mu \mathrm{l}$ & $10 \mathrm{pmoles}$ & 1.0 \\
\hline Rp & $10 \mathrm{pm} / \mu \mathrm{l}$ & $10 \mathrm{pmoles}$ & 1.0 \\
\hline Water & $\mathrm{NA}$ & $\mathrm{NA}$ & 10.86 \\
\hline Total & & & $\mathbf{2 0}$ \\
\hline
\end{tabular}

For genotyping of the TD mapping population, the above primer dilutions were made. The stocks of primers were centrifuged at $13,000 \mathrm{rpm}$ for $1 \mathrm{~min}$ to ensure proper settling to the bottom of the tubes. The primers were then dissolved in sterile Milli Q water; then vortexed and centrifuged for a few seconds to ensure proper dissolution. The stock solutions were prepared as $1 \mathrm{ng} / \mu \mathrm{l} .2 \mu \mathrm{l}$ of the stock solution was diluted in $198 \mu$ l of sterile MQ water to have a diluted solution of $10 \mathrm{ppm} / \mu \mathrm{l}$. The PCR components were then added according to the calculations shown above.

The PCR amplifications were performed in 96 well microtiter plates. The amplification started with a denaturation step at $94^{\circ} \mathrm{C}$ for 30seconds, the annealing temperature of $55^{\circ} \mathrm{C}$ for 30seconds, anextension temperature of $72^{\circ} \mathrm{C}$ for $1 \mathrm{~min}$. with a final extension at $72^{\circ} \mathrm{C}$ for 5 mins. The samples were stored at $4^{\circ} \mathrm{C}$. The amplified products were run on $3 \%$ agarose gels to look for polymorphism.

\section{Electrophoresis buffers: TBE (Tris borate EDTA)}

\begin{tabular}{|c|c|c|}
\hline Buffer & Stock solution & Working solution \\
\hline TBE & $10 \mathrm{X}$ & $1 \mathrm{X}$ \\
& 108g of Tris base & 9mM Tris borate \\
& $\begin{array}{c}55 \mathrm{~g} \text { of boric acid } \\
7.4 \mathrm{~g} \text { of EDTA }\end{array}$ & $2 \mathrm{mM}$ EDTA \\
\hline
\end{tabular}

TBE was made and stored as a $10 \mathrm{X}$ stock solution. The $\mathrm{pH}$ of the concentrated stock buffer was adjusted to $\sim 8$. The concentrated stock buffer was diluted to $1 \mathrm{X}$ just before use and the gel solution and the electrophoresis buffer was made from the same concentrated stock solution.

\section{BPB (Bromophenol Blue)}

10X loading dye was made as follows- 0.25 $\%$ (w/v) BPB, 70\% Glycerol, 30\% 0.5M EDTA. The dye was diluted to $1 \mathrm{X}$ while loading samples.

\begin{tabular}{|c|c|}
\hline Stock solution & Working solution \\
\hline $\mathbf{1 0} \mathbf{m g} / \mathbf{m l}$ & $0.4 \mathrm{mg} / \mathrm{ml}$ \\
\hline
\end{tabular}

$\mathrm{EtBr}$ (Ethidium Bromide):

$0.8 \mathrm{~g}$ of agarose was weighed and $100 \mathrm{ml}$ of TBE (1X) was added. The solution was heated till agarose dissolved. The gel solution was slightly cooled and $2 \mu \mathrm{l}$ of $\mathrm{EtBr}$ was added, mixed and allowed to cool. The gel was poured before solidification in gel casting tray with combs inserted and was allowed to solidify. $0.8 \%$ agarose gel was ready and was transferred to electrophoresis unit filled with 1x TBE buffer. For loading: $1 \mu 1$ of DNA + 
1 $\mu 1$ 10x Bromophenol Blue $+8 \mu 1$ of double distilled water was taken. The DNA samples were loaded in successive wells one by one. Electrophoresis chamber was set with power pack (120V) and the current was switched on. After sometime when the dye-front advanced to approx. $3 / 4^{\text {th }}$ the total distance the power pack was switched off. The gel was then taken out and put on the transilluminator was transferred on to the gel doc and a photograph was taken. Visual intensity of the DNA samples was compared with that of the known (standard) concentration of $\lambda \mathrm{DNA}$.

\section{Results and Discussion}

The 14 SSR primer pairs that generated 16 polymorphic markers were added to the preexisting TD map consisting of 881 markers that included 298 IP, 1 SNP, 73 SSR and 509 AFLP markers. The genotyping data of these 16 markers were obtained by scoring the segregation of the parental alleles in the mapping population (Fig. 1). The individual with a parental allele from TM-4 was scored as ' $a$ ' and that with a Donskaja-IV allele was scored as ' $b$ '. The genotyping data were then used for mapping using JoinMap 4.0 through regression mapping algorithm. All SSR markers were added to the pre-existing map containing 891 markers, Defined linkage groups i.e. 18 which represent the haploid chromosome number of $B$. juncea were identified with a LOD value of 7.0.

The mapping was carried out only for the linkage groups that had an SSR marker, used in the present study. These 16 markers were mapped to $12 \mathrm{LGs}$, of which two markers were mapped to 3 LG sA1, B4 and A8 each and to the remaining 9 LGs (A2, A3, B5, A7, $\mathrm{A} 9, \mathrm{~B} 1, \mathrm{~B} 2$ and $\mathrm{B} 3$ ) one marker, each was mapped (Fig. 1). The 12 LGs covered a total genetic length of $1086.141 \mathrm{cM}$ of the B.juncea genome. However, the AFLP markers can be replaced, once all the polymorphic markers $(\sim 600)$ available in the lab will be used for mapping.

Fig.1 Representative Gel picture of marker profiles of TD DH population with UGM 850

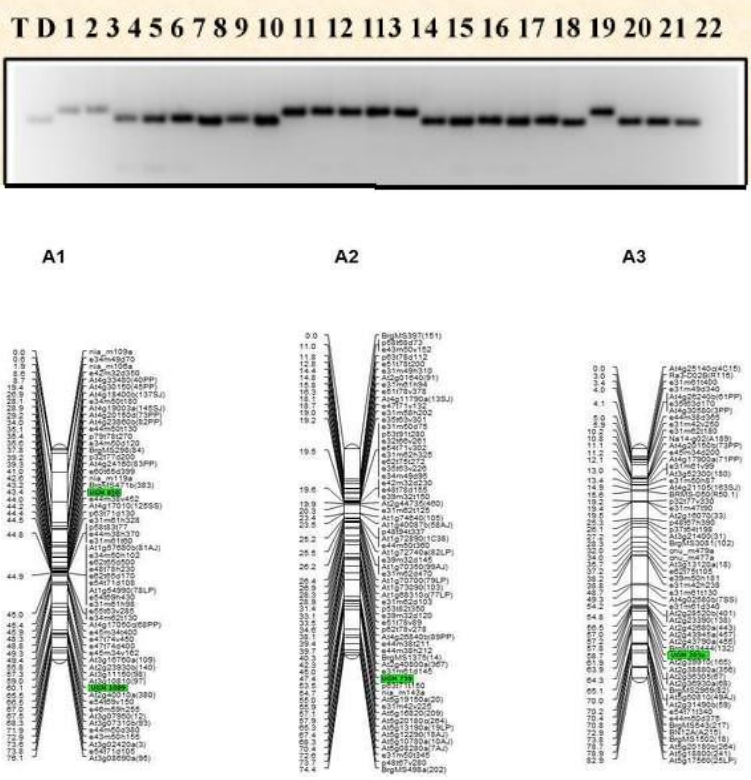



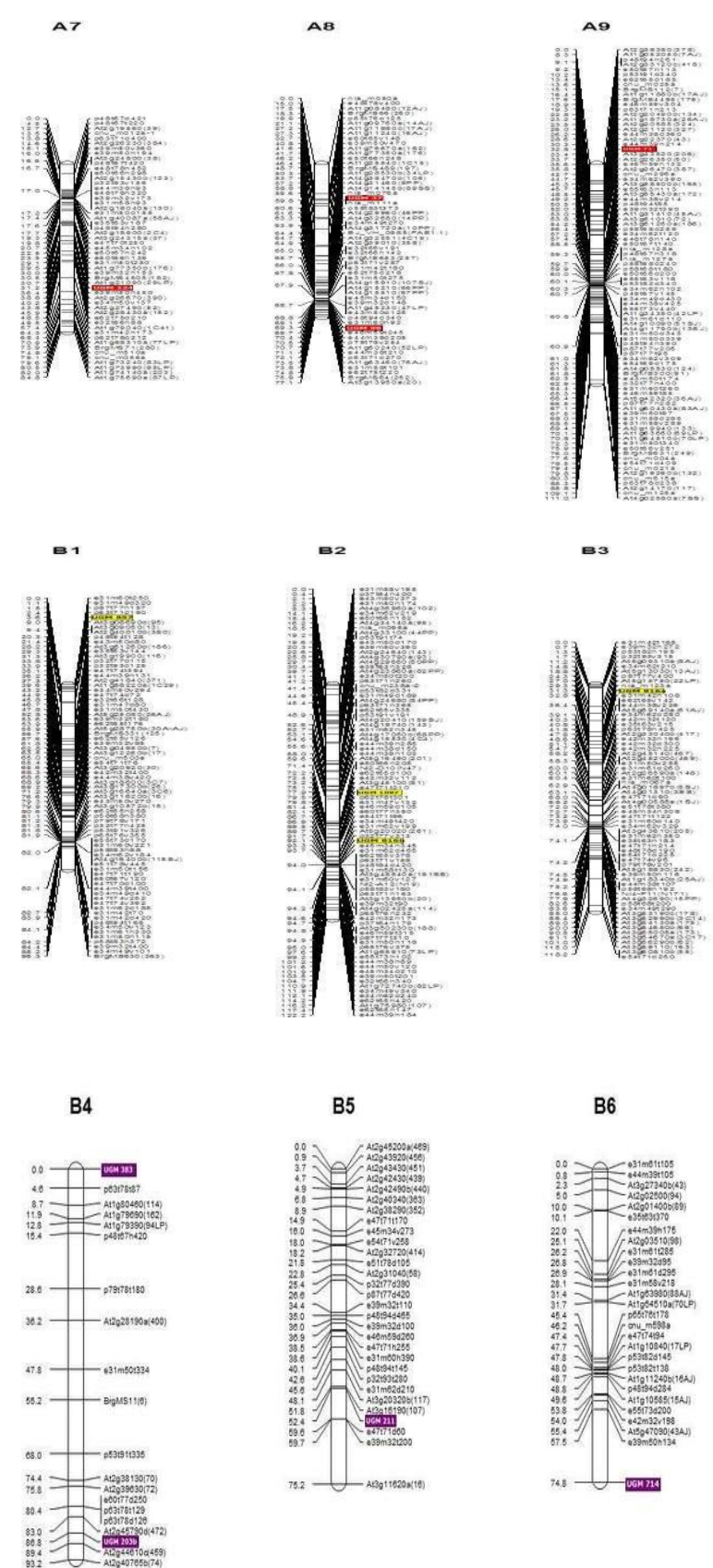

In conclusion the present study, a linkage map was developed by adding 16 SSR markers to a pre-existing linkage map predominantly consisting of AFLP markers. Due to the preference of SSR markers over AFLPs, here we have attempted to replace the AFLP markers of the pre-existing linkage map. The SSR markers used in the present study and their polymorphism status between the parental lines were available in the lab. Using the polymorphic markers, the TD mapping population was genotyped through agarose gel electrophoresis. The genotyping data obtained, were integrated to the pre-existing TD linkage map containing intron polymorphism markers and AFLP markers. The markers were found to be distributed over 12 LGs, covering a genetic length of $1086.141 \mathrm{cM}$ 


\section{References}

Chauhan JS, Singh KH, Singh VV, Kumar S (2011)Hundred years of rapeseedmustard breeding in India: accomplishments and future strategies .Indian J AgricSci 81(12):1093-1109

Dhaka N, Rout K, Yadava SK, Sodhi YS, Gupta V (2017) Genetic dissection of seed weight by QTL analysis and detection of allelic variation in Indian and east European gene pool lines of Brassica juncea. TheorAppl Genet.

Edel, V. (1998). Polymerase Chain Reaction in Mycology: an Overview. In D. A. P.D. Bridge, Applications of PCR IN $M Y C O L O G Y$ (p. 1). Cambridge: CAB INTERNATIONAL.

El Naggar, S.M. (1987). Studies of the family Cruciferae in Egypt. $\mathrm{PhD}$ thesis, Assiut University.

El Naggar, S.M. \& M.N. El Hadidi. (1998). The tribe Alysseae Hayek (Brassicaceae) in Egypt. J. Union Arab Biol. Cairo 6: 501-520.

forages.oregonstate.edu (2015-12-13), Molecular Linkage Maps.

Franzke, A., M. A. Lysak, I. A. AlShehbaz, M. A. Koch and K. Mummenhoff (2011). Cabbage family affairs: the evolutionary history of Brassicaceae. Trends in plant science 16(2): 108116.
Griffiths, Anthony JF; Miller, Jeffrey H.; Suzuki, David T.; Lewontin, Richard C.; Gelbart, William M. (2000-01-01). "Mapping with molecular markers".

Keb-Llanes et al. (2002), Plant Molecular Biology Reporter, 20: 299a-299e

Kumar, A. (2014). Detection of Transgene by Southern Blot Analysis. In S. G. A. Kumar, Techniques in Genetic Engineering (p. 137). New Delhi, Bangalore: Panima Publishing Corporation.

Pradhan, A. K. and D. Pental (2011). Genetics of Brassica juncea. Genetics and Genomics of the Brassicaceae, Springer: 323-345.

Singh, B. (2001). Molecular Markets and Marker-Assisted Selection. In B. SINGH, PLANT BREEDING: Principles \& Methods (pp. 696, 697, 700). New Delhi: KALYANI.

Warwick, S. and I. AlShehbaz (2006). Brassicaceae: chromosome number index and database on CDRom. Plant Systematics and Evolution 259(24): 237-248.

Wittkop B, Snowdon RJ, Friedt W (2009) Status and perspectives of breeding for enhanced yield and quality of oilseed crops for Europe. Euphytica170:131140.

\section{How to cite this article:}

Darshana Patra. 2020. Linkage Map Development in Brassica juncea using SSR. Int.J.Curr.Microbiol.App.Sci. 9(12): 2130-2137. doi: https://doi.org/10.20546/ijcmas.2020.912.250 